\title{
SIMBOLISASI PENGALAMAN SOSIAL MANUSIA MELALUI KARAKTERISTIK ANEMON DALAM BENTUK KERAMIK BIOMIMICRY
}

\author{
Nur Hardiansyah
}

\begin{abstract}
This work is created as exspression of social human experiences then describe through the anemone texture and biomimicry form in the ceramic work. Those artistic work can take part of the art visual element and can be used as interior accent with innovative display. The process of final exam starts with finding the main idea of creation, making sketch, choosing materials, then doing the work. Whereas the processing of work uses various techniques, for example coiling, pinching and molding to show of gesture and movemen of anemone characters. The next step are drying, burning, glazing, and the last displaying. Step by step all those processes are done carefully. Because of ceramic materials needs special treatment, as same as the journey of human life also needs special attention. Doing this ceramic art which about anemone needs good skill, special treatment, and some theories that fixed the concept, these are; the anatomy of anemone, semiotics theory, contemporary design of ceramic, and biomimicry, so the final result, this works have good qualities and can be held responsible. All this work are the social and personal visualization of experiences and observation of environment of the author. Learning from the anemone that has various colours and endless form the author get ideas to express the work in ceramic biomimicry.
\end{abstract}

Key word : Anemone, Biomimicry, Ceramic

\section{INTISARI}

Karya keramik ini diciptakan sebagai bentuk ekspresi pengalaman sosial manusia yang kemudian digambarkan melalui tekstur anemon dan bentuk biomimicry pada karya keramik. Karya anemon dengan bentuk artistik dapat menempati elemen rupa dan digunakan sebagai aksen interior dengan tatanan display yg inovatif. Diawali dengan mencari sumber penciptaan, membuat sketsa, pemilihan bahan, sampai pada tahapan pengerjaan karya itu sendiri. Dalam proses berkarya ini menggunakan berbagai macam tehnik, yaitu pilin, pijat dan cetak untuk membuat gestur dan gerakan yang menjadi identitas anemon pada karya keramik. Kemudian dilanjutkan dengan tahapan pengeringan, pembakaran, penggelasiran, dan terakhir pemajangan karya. Semua proses tersebut harus dijalankan dengan teliti dan satu-persatu. Dikarenakan keramik mejadi material yang memang membutuhkan kehati-hatian, sama halnya dengan perjalanan kehidupan manusia. Semua pengerjaan karya keramik anemon yang membutuhkan keterampilan dan perlakuan khusus tentu saja akan lebih diperkuat dengan teoriteori yang mendukung ide dan konsep karya tersebut, teori pendukungnya antara lain: anatomi tubuh anemon, teori semiotika, keramik dalam dunia desain kontemporer, wujud dalam bentuk biomimicry, sehingga karya memiliki kekuatan dan bisa dipertanggung jawabkan. Hasil karya yang penulis ciptakan merupakan visualisasi pengalaman yang diperoleh dari pengamatan

*) Nur Hardiansyah, Mahasiswa Program Studi S-1 Kriya Seni Jurusan Kriya, Fakultas Seni Rupa, Institut Seni Indonesia Yogyakarta. 
lingkungan, baik secara sosial maupun personal. Kita bisa belajar dari kehidupan anemon ini, salah yang ternyata memiliki keanekaragaman dalam warna dan bentuk tak ada habisnya jika dipelajari, dengan penggunaan karakter anemon penulis mendapatkan ide dalam mewujudkan karya-karya keramik biomimicry.

Kata kunci : Anemon, Biomimicry, Keramik

\section{PENDAHULUAN}

\section{Latar Belakang Penciptaan}

Bumi memiliki banyak sekali kehidupan, diantaranya adalah kehidupan bawah laut yang biasa orang ketahui sebagai ekosistem bawah laut. Pada ekosistem bawah laut terdapat banyak sekali organisme (makhluk hidup) baik itu yang ber-sel satu maupun ber-sel dua dan juga yang bertulang belakang ataupun yang tidak bertulang. Salah satu organisme bawah laut yang akan dijadikan sebagai ide acuan pembuatan karya keramik adalah anemon laut.

Menyelam ke dasar laut merupakan salah satu impian bagi penulis, namun belum pernah memberanikan diri melakukannya. Karena impian dan imajinasi tersebut, penulis yang membayangkan bagaimana bentuk anemon laut dan mencari referensi dari pustaka, baik melalui buku maupun gambar visual. tema anemon laut inilah yang mendorong konsep dan ide penciptaan karya Tugas Akhir karena anemon laut merupakan binatang laut yang diam tetapi sewaktu-waktu bisa sangat dinamis dan ekspresif.

Gerak anemon laut yang dinamis juga ekspresif dapat membuat karya yang diangkat juga dinamis karena mengambil gestur dan gerak anemon laut tersebut, disisi lain banyak terdapat jenis anemon yang hidup di lautan yang membuatnya memiliki tekstur yang beragam dan keunikan pada masing- masing jenisnya. Penulis juga tertarik pada karakteristik sosial manusia dan kepribadian manusia sehingga ingin membuat simbolisasi dari karakter manusia melalui bentuk keramik anemon. Simbolisasi tersebut direpresentasikan pada bentuk keramik menggunakan tekstur, gestur dan gerakan tentakel anemon.

Bentuk anemon yang mewakili simbolisasi pengalaman sosial manusia tidak hanya sampai pada bentuk nyata anemon yang berada di alam, tetapi penulis ingin mengambil komposisi bentuk, tekstur dan gestur anemon menjadi suatu bentuk baru. Bentuk alam organik dalam hal ini yaitu anemon tidak direpresentasikan secara langsung melainkan imajinatif dan abstrak kemudian dilakukan pendekatan dalam perancangan bentuk yang diaplikasikan pada bagian atau keseluruhan bentuk/karya yang merupakan hasil analogi biologi, di dalam dunia desain dikenal dengan istilah biomimicry dan dalam arsitektur dikenal dengan biomorfik.

Dari latar belakang yang dijabarkan penulis mengharapkan dapat memvisualisasikan pengalaman sosial manusia melalui artistik anemon dalam bentuk keramik biomimicry. Sepengetahuan penulis ide ini masih jarang digunakan dalam bidang seni rupa, karena belum banyak seniman yang mengangkat anemon sebagai inspirasi berkarya. 


\section{Hasil dan Pembahasan}

Proses penciptaan ini menghasilkan 8 karya yang berupa keramik instalasi yang terdiri dari 5 instalasi 2 dimensi/dinding dan 3 instalasi 3 dimensi/ruang. Gambargambar di bawah ini merupakan karya yang telah diciptakan.

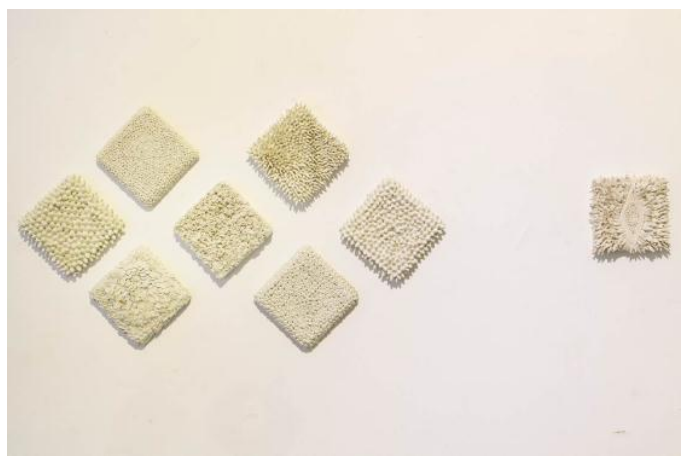

Judul : D.I.D (Dissosiative Identity Disorder)

Media : Bone Chine, Bergelasir

Ukuran : Matra Bervariasi

Foto : Benny Kurniadi

Tahun : 2015
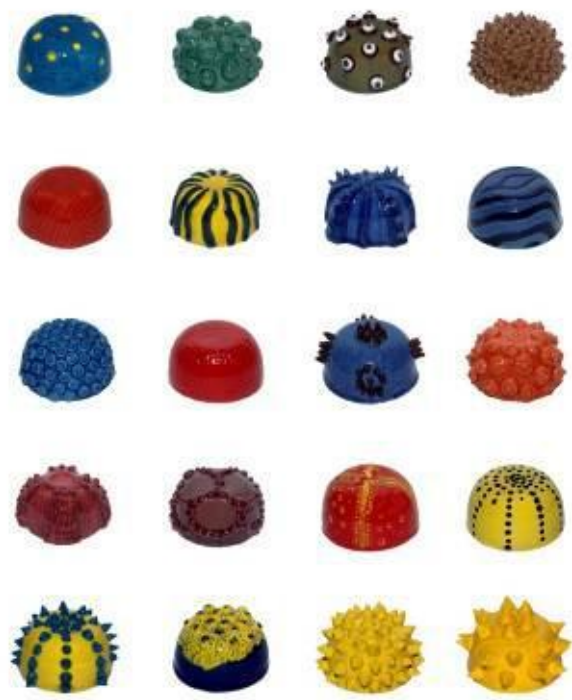

Judul : Intimitation (Intim-Imitasi)

Media : Bone Chine Berwarna, Acrilyte Display Ukuran : Matra Bervariasi, Foto : Benny Kurniadi Tahun : 2015

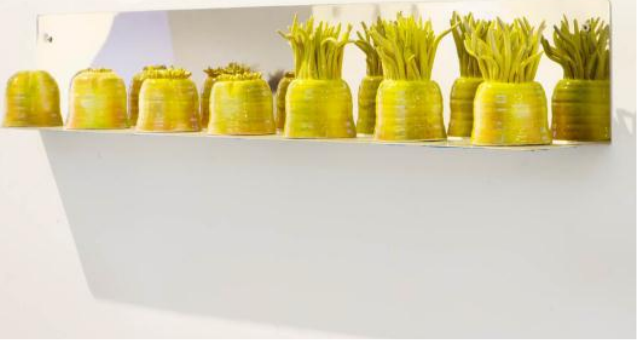

Judul : Grow in Tone

Media :Stoneware, Gelasir Engobe, Stainless Hanging Ukuran : Matra Bervariasi

Foto : Benny Kurniadi

Tahun : 2015

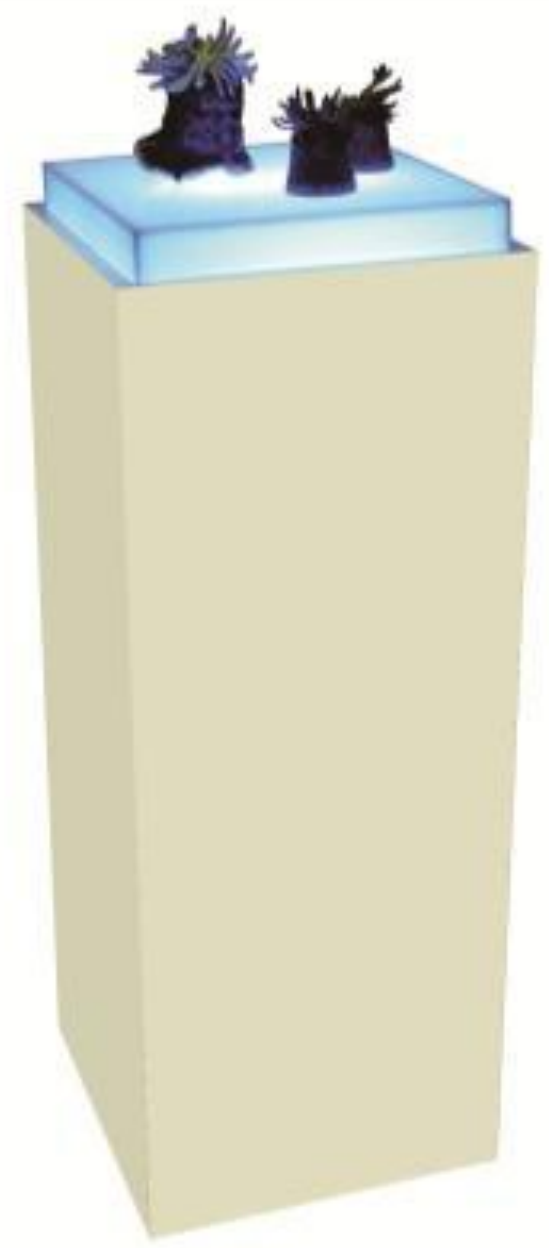

Judul : 1 To 3

Media : Stoneware Bergelasir, Acrilyte Display, Lampu Neon, Pedestal Kayu

Ukuran : $30 \times 30 \times 100 \mathrm{~cm}$

Foto : Benny Kurniadi

Tahun : 2014 


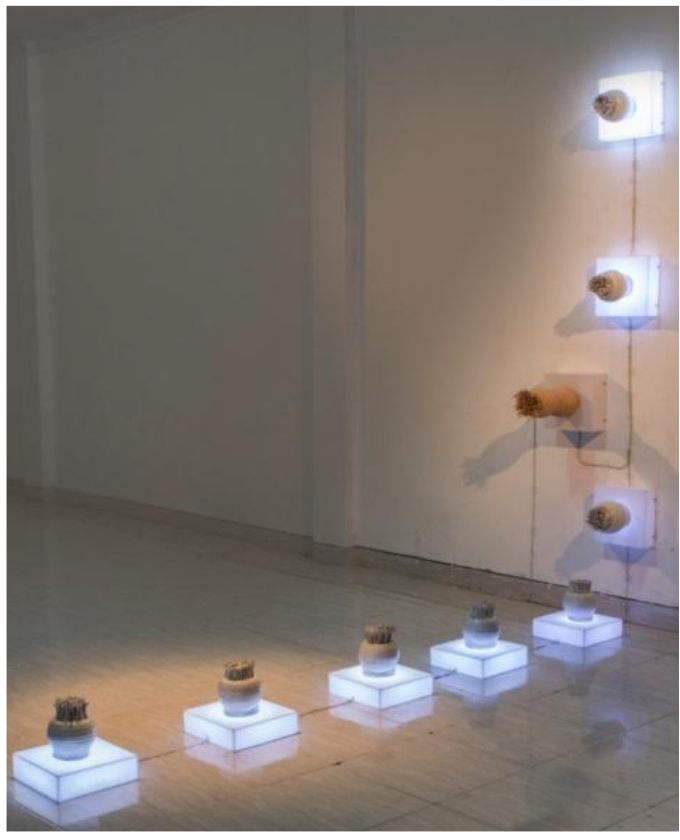

Judul : Story

Media : Stoneware, Gelasir Engobe, Acrilyte Display, Kabel, LED

Ukuran : Matra Bervariasi

Foto : Benny Kurniadi

Tahun : 2015

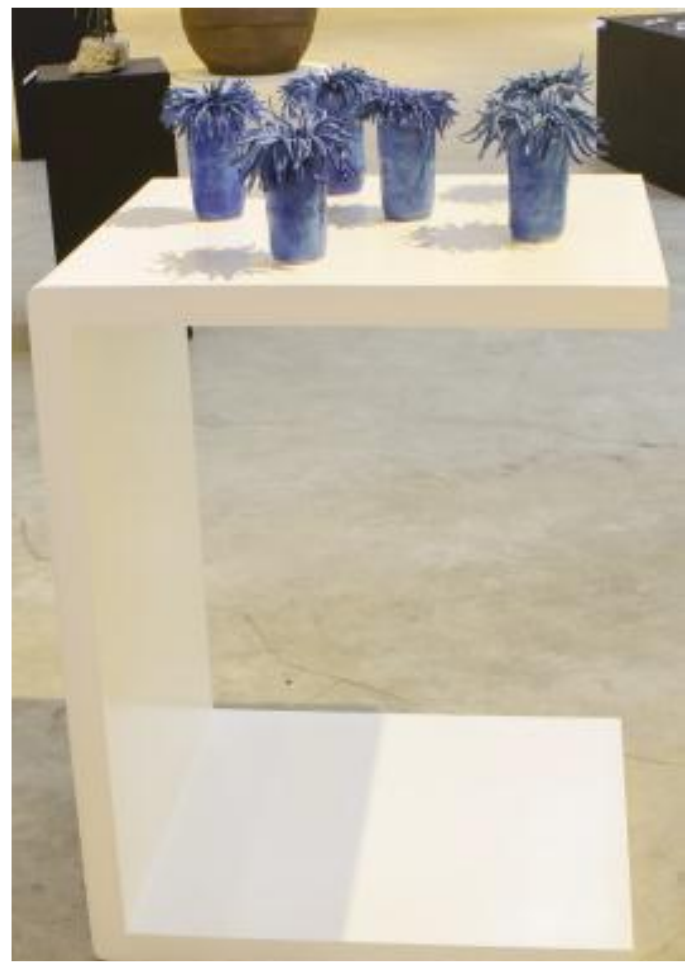

Judul : Biru Lambai Melambai

Media : Stoneware, Gelasir Engobe, Pedestal Kayu Ukuran : $70 \times 60 \times 107$

Foto : Benny Kurniadi

Tahun : 2015

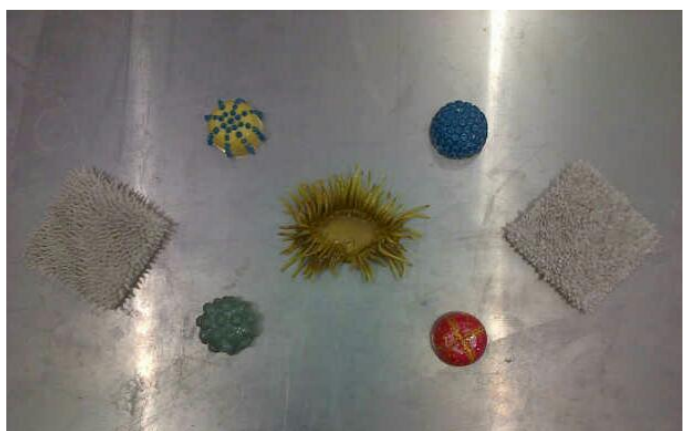

Judul : Unity in Diversity

Media : Stoneware, Gelasir Engobe, Bone Chine berwarna

Ukuran : $50 \times 50 \times 8 \mathrm{~cm}$

Foto : Benny Kurniadi

Tahun : 2015

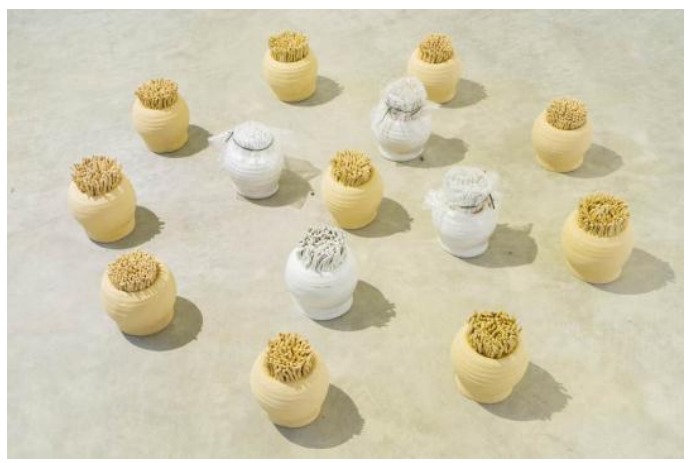

Judul : Lingkaran Kehidupan Melingkar

Media : Stoneware, Gelasir Engobe

Ukuran : Matra Bervariasi

Foto : Benny Kurniadi

Tahun : 2015

\section{Tinjauan Karya}

Jenis bahan baku yang digunakan adalah tanah liat jenis stoneware murni dari Sukabumi, selain stoneware Sukabumi murni penulis juga menggunakan tanah bone chine untuk beberapa karya dengan suhu bakar 1000-1200ㄷ. Kedua bahan tersebut mempengaruhi proses pembentukan karya keramik anemon. Karakteristik bahan tersebut mampu menjadikan bentuk sesuai dengan apa yang diharapkan. Untuk pembentukan karya yang lebih dinamis menggunakan tanah stoneware Sukabumi dan pewarnaannya menggunakan gelasir engobe. Untuk 
beberapa karya lainnya yang membutuhkan warna cerah guna menimbulkan efek karakteristik warna dan tekstur Anemon menggunakan bone chine dengan ditambah dengan stain (bahan pewarna gelasir) dan waterglass dengan perbandingan tertentu.

Teknik yang digunakan pada proses pembuatan tugas akhir ini meliputi: teknik slab, teknik pinch, teknik pilin, cetak tuang (slipcasting) dan cetak padat (moulding). Selain itu pada proses dekorasi/pembentukkan menggunakan teknik tempel (sprigg) dan gores (scratch). Semua teknik yang diterapkan telah memberikan kreasi, kedinamisan dalam pembuatan karya dan menghasilkan karya yang sesuai dengan harapan.

Bentuk karya pada tugas akhir ini telah memenuhi harapan penulis. Bentukbentuk abstraksi anemon dengan menggunakan bentuk keramik biomimicry sudah sesuai dengan data acuan dan rancangan karya yang ada. Hasil tersebut telah memberikan kepuasan bagi penulis, karena tekstur dan kedinamisan yang dituangkan dalam karya mampu tersalurkan dengan baik.

Pewarnaan dalam pengerjaan keramik anemon ini menggunakan 2 teknik pewarnaan yaitu gelasir engobe dan pewarnaan tanah dengan stain (pewarna gelasir) sehingga tanah memiliki unsur warna yang diinginkan seperti: putih, merah, biru, hijau, jingga, kuning , ungu dan coklat. Selain itu pewarnaan dengan 2 teknik tersebubt memberikan nilai clean and perfect (keramik bersih) karena menggunakan tungku listrik.

Bentuk keramik biomimicry ini merupakan pendeskripsian dari keinginan manusia yang ingin intim dengan suatu hal (digambarkan dengan tekstur dan bentuk) namun hal tersebut hanyalah imitasiartificial-tiruan yang dibuat-buat. Konsep bentuk Biomimicry digunakan untuk pengabstraksian visual agar yang melihat ingin mengetahui objek apa yang dilihat sebenarnya.

Manusia memiliki keinginan untuk mengimitasi/mencontoh dirinya untuk menjadi sesuatu yang berbeda, seperti individu yang memiliki karakter keras tetapi demi karirnya dia mengganti karakternya (persona) menjadi seseorang yang baik dan ramah, seakan-akan karakter tersebut bukanlah hal yang dibuat-dibuat melainkan jati diri yang sebenarnya. Sama halnya dengan seorang seniman dalam berkarya, terkadang beberapa seniman memiliki kecendurangan untuk mengimitasi sesuatu dari alam atau dari karya seniman lain dan ingin intim dengan karakter karya/material yang dibawakan. 8

Pada masing-masing warna keramik Biomimicry ini terdapat warna-warna yang menginterpretasikan alam (nature) dalam artian luas, seperti warna pada buahbuahan, bunga, dan organisme hidup lainnya.

\section{Kesimpulan}

Bagi penulis, pengalaman pribadi dan pengamatan dari sekitar lingkungan merupakan awal dari berkarya seni. Dari dua hal tersebut, muncul gejolak dalam diri kemudian terciptalah ide atau gagasan. Pada akhirnya, ide atau gagasan tersebut dituangkan ke dalam karya seni sebagai wujud dari ekspresi. Mengekspresikan diri dalam suatu karya seni merupakan suatu bentuk kebebasan bagi setiap individu. Setiap individu (seniman) jelas memiliki 
latar dan karakter yang berbeda-beda. Karena perbedaan itulah yang menjadi ciri khas dari personal masing-masing.

Ide penciptaan karya Tugas Akhir ini berawal dari ketertarikan penulis terhadap bentuk, karakteristik tekstur dan warna anemon dengan pengalaman pribadi dan sosial yang kemudian diekspresikan melalui abstraksi bentuk keramik biomimicry. Dalam proses penciptaan karya ini, penulis mengabtraksi bentuk-bentuk dan karakteristik anemon, yang diambil dominan dari bentuk anemon tabung. Anemon jenis ini banyak dijadikan sebagai ide penciptaan bentuk oleh senimanseniman luar Indonesia namun pada penciptaan Tugas Akhir ini anemon Tabung di deformasi menjadi bentuk keramik biomimicry. Sehingga bentuk anemon tidak dibuat apa adanya, yang diterapkan pada karya adalah keunikan tentakel, tekstur pada anemon tersebut dan kemudian tercipta keramik dengan bentuk baru tidak seutuhnya anemon namun yang melihatnya dapat memastikan kalau ini merupakan bentuk dari biota laut. Oleh Karena itu, Delapan karya keramik ini memiliki makna, cerita dan arti yang berbeda-beda sesuai dengan ide dari pengalaman pribadi dan ketertarikan terhadap pengalaman sosial pada masyarakat. Kemudian keramik tersebut disusun dalam tatanan display yang sesuai dengan pemaknaan karya masing-masing.

\section{DAFTAR PUSTAKA}

\section{Buku}

Astuti, Ambar, Pengetahuan Keramik, Yogyakarta: Gajah Mada University Press, 1997
Astuti, Ambar, Keramik Bahan Cara Pengerjaan Gelasir, Yogyakarta: Arindo Nusa Media, 2008

Benyus, Janine. Biomimicry-Innovation Inspired by Nature. New York: Harper Collins Published, 1997

Budiman, Kris, Semiotika Visual: Konsep, Isu dan Problem Ikonisitas, Yogyakarta, Jala Sutra, 2011

Castro, Peter \& Michael E. Huber, Marine Biology Second Edition, USA: McGraw-Hill Companies, Inc, 1997

Chodijah, Moh. Alim Zaman, Desain Mode Tingkat Dasar Jakarta: Meutia Cipta Sarana Bersama Ikatan Penata Busana Indonesia "Kartini", 2001

Ebdi Sanyoto, Sadjiman, Nirmana ElemenElemen Seni dan Desain, Yogyakarta: Jala Sutra, 2009

Collins, Peter, Changing Ideals in Modern Architecture, 1750-1950, Montreal: McGill-Queens University Press. 1998

Feldman, Edmun Burke, (Gustami: Pent), Art, Image and Idea, New Jersey: Prentic-Hall, inc. Englewood Cliffsd, 196710

Gatot Budiyanto, Wahyu, Kriya Keramik, Jakarta: Departemen Pendidikan Nasional, 2008

Gustami, Sp., Butir-Butir Mutiara Estetika Timur :Ide Dasar Penciptaan Seni Kriya Indonesia, Yogyakarta: Prasista, 2007

Kassem, Kane \& Eric Madeja, The Coral Triangle, U.K: Jhon Beaufoy Published Unlimited, 2012

Pauline Busch (Christine Pangemanan: Pent) , Widya Wiyata Pertama Anak- 
Anak: Kehidupan dalam Air, Jakarta: Educational Technologies Limited, 1999

Susanto, Mikke, Diksi Rupa: Kumpulan Isvbgtilah dan Gerakan Seni Rupa, Yogyakarta: Dicti Art Lab, 1997

SP. ,Soedarso, Tinjauan Seni Sebuah Pengantar Untuk Apresiasi Seni, Yogyakarta: Saku Dayar Sarana, 1987

The 3rd Jakarta Contemporary Ceramics Biennale :Coefficient of Expansion Jakarta: Kementrian Pariwisata dan Ekonomi Kreatif Republik Indonesia, Galeri Nasional, Indonesia, Jakarta, 23 September-13 Oktober 2014

W. Nyebakken, James, (Muhammad Eidman: Pent), Marine Biologi: an ecological approach, Jakarta: PT Gramedia Pustaka, 1988

\section{WEBTOGRAFI}

\section{Tulisan Jurnal Online}

Wunsche., Isabel, Biological Methapors in 20-th Century Art and Design. YLEM Journal 828 July-August 2003, Artists Using Science \& Technology number 11 formerly YLEM newsletter. Biological Methapors, Idea Generation, http://www.ylem.org/journal/2003/Issl08/ vol23.pdf (diakses pada tanggal 3 Maret 2015 Pukul 22:30)

\section{Gambar}

http://www.slideshare.net/immariandra/p ower-point-coelenterata (diakses pada tanggal 12 Desember 2014 pukul 23:20 WIB)

http://www.heatherknightceramics.com/in dex.html (diakses pada tanggal 10 September 2014 pukul 01.00 WIB) http://www.slideshare.net/immariandra/p ower-point-coelenterata (diakses pada tanggal 12 Desember 2014 pukul 23:30 WIB)

http://www.googleimage.com/anemonedeep-blue-sea/issord (diakses pada tanggal 12 Desember 2014 pukul 20:42).

http://www.googleimage/mazizphoto/1qwp (diakses pada tanggal 13 Desember 2014 pukul 21:42)

http://www.flickrhivemind.net/User/kapel entzi/Timeline (diakses pada tanggal 3 Februari 2015 pukul 20:22).

http://www.dennisonpottery.com/\#!masks /c1qwg (diakses pada tanggal 20 Januari 2015 pukul 20:44). 12

https://www.etsy.com/listing/218492127/ turquoise-chartreuse-orange-and green?ref=related- (diakses pada tanggal 15 September 2014 pukul 21:55).

https://www.etsy.com/listing/218492127/ red-blue-and-yellow?ref=related-5 (diakses pada tanggal 15 September 2014 pukul 22:15). 